\title{
TPA-induced p21 expression augments G2/M arrest through a p53-independent mechanism in human breast cancer cells
}

\author{
JEONGHUN HAN $^{1 *}$, SANGMIN KIM $^{1 *}$, JUNG-HYUN YANG $^{2}$, SEOK JIN NAM $^{1}$ and JEONG EON LEE ${ }^{1}$ \\ ${ }^{1}$ Department of Surgery, Samsung Medical Center, Sungkyunkwan University School of \\ Medicine, 50 Irwon-dong, Gangnam-gu, Seoul; ${ }^{2}$ Department of Surgery, Konkuk University \\ Medical Center 4-12, Hwayang-dong, Gwangjin-gu, Seoul, Republic of Korea
}

Received August 1, 2011; Accepted September 23, 2011

DOI: $10.3892 /$ or.2011.1511

\begin{abstract}
The tumor promoter, 12-O-tetradecanoylphorbol13-acetate (TPA), has a differential role on the regulation of the cell cycle in a variety of tumor cells. The mechanism between TPA and the cell cycle in breast cancer is not fully understood. Therefore, we investigated the regulatory mechanism of TPA on control of the cell cycle of breast cancer cells. Our results showed that TPA increased the level of p21 expression in MCF-7 cells with wild-type p53 and MDA-MB-231 cells with mutant p53 in a dose-dependent manner. In contrast, TPA decreased the expression of p53 in MCF-7 cells, but did not affect MDA-MB-231 cells. We next examined the regulatory mechanism of TPA on p21 and p53 expression. Our results showed that the TPA-induced up-regulation of p21 and down-regulation of p53 was reversed by UO126 (a MEK1/2 inhibitor), but not by SP600125 (a JNK inhibitor) or SB203580 (a p38 inhibitor), although TPA increased the phosphorylation of ERK and JNK in MCF-7 cells. In addition, the TPA-induced arrest of the $\mathrm{G} 2 / \mathrm{M}$ phase was also recovered by UO126 treatment. To confirm the expression of p21 through the MEK/ERK pathway, cells were transfected with constitutively active (CA)-MEK adenovirus. Our results showed that the expression of p21 was significantly increased by CA-MEK overexpression. Taken together, we suggest that TPA reciprocally regulates the level of p21 and p53 expression via a MEK/ ERK-dependent pathway. The up-regulation of $\mathrm{p} 21$ in response to TPA is mediated through a p53-independent mechanism in breast cancer cells.
\end{abstract}

Correspondence to: Dr Jeong Eon Lee, Department of Surgery, Samsung Medical Center, Sungkyunkwan University School of Medicine, 50 Irwon-dong, Gangnam-gu, Seoul 135-710, Republic of Korea

E-mail: paojlus@hanmail.net

${ }^{*}$ Contributed equally

Key words: p21, p53, 12-O-tetradecanoylphorbol-13-acetate, ERK, cell cycle

\section{Introduction}

Phorbol esters, such as 12-O-tetradecanoylphorbol-13-acetate (TPA), are natural molecules that are well-known tumor promoters and reversible activators of protein kinase $\mathrm{C}$ (PKC) (1). TPA may act as a potential inducer of tumor invasion and migration in various tumor cells, as well as a trigger of diverse cellular functions, including cell cycle arrest in a variety of tumor cells, such as breast and colon cancer cells (1-4). TPA induces the expression of cyclins $\mathrm{A}$ and $\mathrm{B}$, which are involved in the $\mathrm{S}$ phase and $\mathrm{G} 2 / \mathrm{M}$ transition during cell proliferation in pancreatic cancer cells (5). However, TPA increases the cell proliferation of fibroblasts and several cancer cell lines, such as KG-1 human leukemia cells and ZR75-1 human breast cancer cells $(6,7)$. To date, the role of TPA is controversial and the exact mechanism by which TPA regulates the cell cycle in breast cancer cells has not been fully elucidated.

The cyclin kinase inhibitor, p21, a universal inhibitor of cyclin-dependent kinases, plays an important role in keeping cells alive after DNA damage and regulates the cell cycle subsequent to p53 induction (6,7). Induction of p21 results in a survival advantage in a wide variety of cells, such as glioblastoma cells (8), muscle cells (9), and macrophages (10). In contrast, the down-regulation of p21 by transfection of antisense oligonucleotides promotes apoptosis in both T47D and MCF-7 human breast cancer cells (11). The amino-terminal binding site of p21 binds to various cyclin/ CDK complexes and is involved with cell cycle progression (12). In addition, the induction of p53 and one of its downstream targets, $\mathrm{p} 21^{\mathrm{waf} 1 / \mathrm{cip} 1}$, is involved in accelerated cellular senescence (13), as well as activation of the G1/S and G2/M cell cycle checkpoints (14).

The tumor suppressor protein, p53, is a transcription factor that can trigger cell cycle arrest, DNA repair, replicative senescence, and apoptosis (15). The level of p53 expression is regulated in a wide variety of cellular stresses which are genotoxic (DNA alterations induced by irradiation, UV, carcinogens, and cytotoxic drugs) and not genotoxic (hypoxia, cell detachment, growth factor deprivation, and oncogene expression) (18). Somatic missense mutations of p53 are found in approximately $50 \%$ of human cancers (16) and are capable of conferring increased tumorigenicity, metastasis, and tumor invasion $(17,18)$. 
In the current study, we investigated the regulatory mechanism of p53 and p21 expression by TPA and the effect of TPA on the control of the breast cancer cell cycle. We showed that the level of expression of p53 and p21 in response to TPA is reciprocally regulated via a MEK/ERK-dependent pathway in MCF-7 breast cancer cells. In addition, TPA-induced p21 mRNA and protein expression was shown to be mediated through a p53-independent mechanism in breast cancer cells.

\section{Materials and methods}

Reagents. Dulbecco's modified Eagle's medium (DMEM) and antibiotics were purchased from Life Technologies (Rockville, MD, USA). Fetal bovine serum (FBS) was purchased from Thermo Fisher Scientific (Waltham, MA, USA). Rabbit polyclonal anti-p21 and $\beta$-actin antibodies were purchased from Abfrontier (Seoul, Korea). Mouse monoclonal anti-p53 and the secondary peroxidase-conjugated antibodies were purchased from Santa Cruz Biotechnology, Inc. (Santa Cruz, CA, USA). UO126 and TPA were purchased from Tocris (Ellisville, MO, USA). ECLplus reagents were purchased from Amersham (Buckinghamshire, UK).

Cell cultures. MDA-MB-231 and MCF-7 cells were cultured in DMEM media and MDA-MB-453 cells were cultured in RPMI-1640 media supplemented with 10\% FBS, 2 mM glutamine, $100 \mathrm{IU} / \mathrm{ml}$ penicillin, and $100 \mu \mathrm{g} / \mathrm{ml}$ streptomycin. Each cell culture was maintained in medium supplemented without FBS for $24 \mathrm{~h}$.

Chemical and/or inhibitor treatment. For experiments, cells were maintained in culture medium supplemented without FBS for 24 h. Culture media were replaced with fresh serumfree media and further incubated with TPA and/or specific inhibitors at $37^{\circ} \mathrm{C}$ for $24 \mathrm{~h}$. UO126 $(10 \mu \mathrm{M})(\mathrm{a}$ MEK $1 / 2$ inhibitor), SP600125 (a JNK inhibitor), or SB203580 (a p38 inhibitor) was added $30 \mathrm{~min}$ prior to TPA treatment.

Western blotting. Cell lysates were used in immunoblot analysis for p53, p21, and $\beta$-actin proteins. Proteins were boiled for $5 \mathrm{~min}$ in Laemmli sample buffer and electrophoresed in $10 \%$ SDS-PAGE gels. Proteins were transferred to PVDF membranes and blocked in $10 \%$ skim milk in TBS with $0.01 \%$ Tween-20 (TBS/T) for $15 \mathrm{~min}$. The blots were incubated with anti-p53, p21 $(1 / 1,000)$, or $\beta$-actin antibodies $(1 / 2,000)$ in TBS/T buffer at $4^{\circ} \mathrm{C}$ overnight. Blots were washed 4 times for $10 \mathrm{~min}$ in $\mathrm{TBS} / \mathrm{T}$ buffer, and subsequently incubated in anti-rabbit peroxidase-conjugated antibody (1/2,000 dilution) in TBS/T buffer for $1 \mathrm{~h}$ at room temperature (RT), then blots were washed 4 times in TBS/T buffer. ECLplus reagents were used for development.

$R T-P C R$. Total RNA was extracted from MCF-7 and MDA-MB-231 human breast cancer cells using TRIzol (Invitrogen, Carlsbad, CA, USA) according to the manufacturer's protocol. Extracted RNA was electrophoresed in 1\% agarose gels to confirm quality and quantity. Equal amounts of RNA $(1 \mu \mathrm{g})$ were reverse-transcribed using a first-strand cDNA synthesis kit (MBI Fermentas, Vilnius, Lithuania). Semi-quantitative PCR was performed using specific primers, as follows: human p53 (forward, 5'-GGC CCA CTT CAC CGT ACT AA-3'; reverse, 5'-AAG CGA GAC CCA GTC TCA AA-3'); human p21 (forward, 5'-GCG ATG GAA CTT CGA CTT TGT-3'; reverse, 5'-GGG CTT CCT CTT GGA GAA GAT-3'); and $\beta$-actin as an internal control (forward, 5'-AAA CTG GAA CGG TGA AGG TG-3'; reverse, 5'-CTC AAG TTG GGG GAC AAA AA-3'). The PCR conditions used were as follows: 1 cycle of initial denaturation $\left(5 \mathrm{~min}\right.$ at $\left.94^{\circ} \mathrm{C}\right) ; 20$ cycles $\left(\beta\right.$-actin) of amplification $\left(1 \mathrm{~min}\right.$ at $94^{\circ} \mathrm{C}, 1 \mathrm{~min}$ at $60^{\circ} \mathrm{C}$, and $1 \mathrm{~min}$ at $72^{\circ} \mathrm{C}$ ), 30 cycles (human p53) of amplification $\left(30 \mathrm{sec}\right.$ at $94^{\circ} \mathrm{C}, 30 \mathrm{sec}$ at $54^{\circ} \mathrm{C}$, and $1 \mathrm{~min}$ at $72^{\circ} \mathrm{C}$ ), or 25 cycles (human p21) of amplification $\left(30 \mathrm{sec}\right.$ at $94^{\circ} \mathrm{C}, 30 \mathrm{sec}$ at $58^{\circ} \mathrm{C}$, and $1 \mathrm{~min}$ at $\left.72^{\circ} \mathrm{C}\right)$; and 1 cycle of final extension $(10 \mathrm{~min}$ at $72^{\circ} \mathrm{C}$ ). Reaction products were electrophoresed in $2 \%$ agarose gels and visualized with ethidium bromide (EtBr).

Flow cytometry analysis (FACS). Cells were trypsinized and harvested by centrifugation at $1,500 \mathrm{rpm}$ for $5 \mathrm{~min}$. The cell pellets were then resuspended in $1 \mathrm{ml}$ of PBS and fixed in 70\% ethanol for $20 \mathrm{~min}$ at RT. The fixed cells were centrifuged and washed twice in PBS to wash out any apoptotic cells. The cells were resuspended in $1 \mathrm{ml}$ of PBS with $100 \mu \mathrm{g} / \mathrm{ml}$ of DNasefree RNase A (Biopure, Canada), then incubated for $30 \mathrm{~min}$ in a $37^{\circ} \mathrm{C}$ water bath. The cells were collected by centrifugation at $1,500 \mathrm{rpm}$, the cell pellets were washed twice with PBS, resuspended in PBS containing $50 \mu \mathrm{g} / \mathrm{ml}$ of propidium iodide (Sigma, St. Louis, MO, USA), then analyzed using FACSvantage (Becton-Dickinson, San Diego, CA, USA).

Adenovirus transfer. The empty (Lac Z) and adenoviral human CA-MEK was the gift of Dr Ha Hyunil (Seoul National University, Korea). Recombinant adenovirus expressing human CA-MEK was reproduced into 293A cells. The expression of this construct was confirmed by Western blotting.

\section{Results}

TPA differentially regulates the expression of p53 and p21 in breast cancer cells. To investigate TPA-induced modulation of the cell cycle, we chose MCF-7 and MDA-MB-231 breast cancer cells. The properties of MCF-7 and MDA-MB-231 breast cancer cells are wild-type p53 and mutant p53, respectively.

To determine the expression of $\mathrm{p} 53$ and $\mathrm{p} 21$ by TPA, MCF-7 and MDA-MB-231 breast cancer cells were treated for the indicated times and concentrations. Our results showed that TPA decreased the level of expression of p53 protein in a timedependent manner (Fig. 1A). In contrast, the level of expression of p21 protein was significantly increased by TPA in MCF-7 breast cancer cells with wild-type p53 (Fig. 1A). Furthermore, we examined the dose-response effect of TPA in MCF-7 breast cancer cells. As shown in Fig. 1B, the level of expression of p53 and p21 protein was reciprocally regulated by TPA. In addition, we investigated these effects in MDA-MB-231 breast cancer cells with mutant p53. We showed that TPA did not affect the level of expression of p53 protein, whereas the level of expression of $\mathrm{p} 21$ was significantly increased by TPA (Fig. 1C). Therefore, we demonstrated that the TPA-induced expression of $\mathrm{p} 21$ was regulated through a p53-independent mechanism in breast cancer cells. 

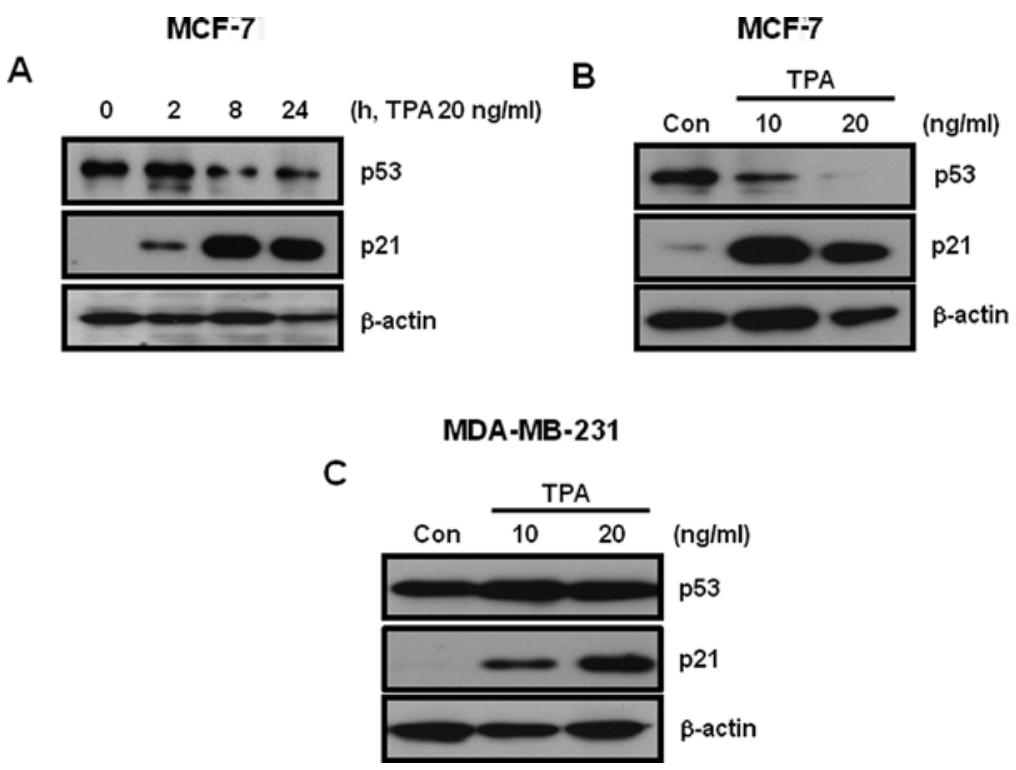

Figure 1. The expression of p53 and p21 in response to TPA in breast cancer cells. (A) After serum starvation for $24 \mathrm{~h}, \mathrm{MCF}-7$ breast cancer cells were treated with $20 \mathrm{ng} / \mathrm{ml}$ of TPA for the indicated times. After serum starvation for $24 \mathrm{~h}$, MCF-7 (B) and MDA-MB-231 (C) breast cancer cells were treated with TPA at the indicated concentrations for $24 \mathrm{~h}$. The expression levels of $\mathrm{p} 53$, p21, and $\beta$-actin protein were analyzed by Western blotting. The results are representative of three independent experiments. Con, control.

A

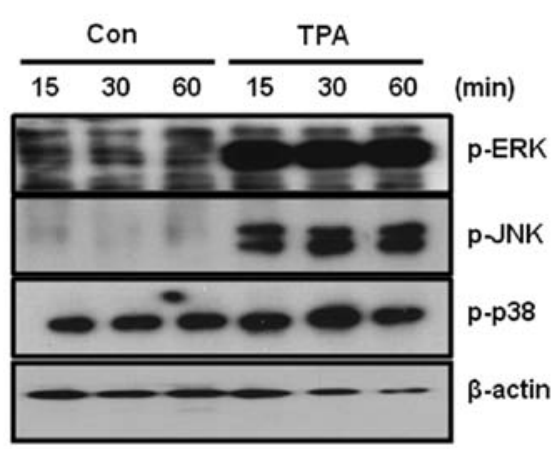

B

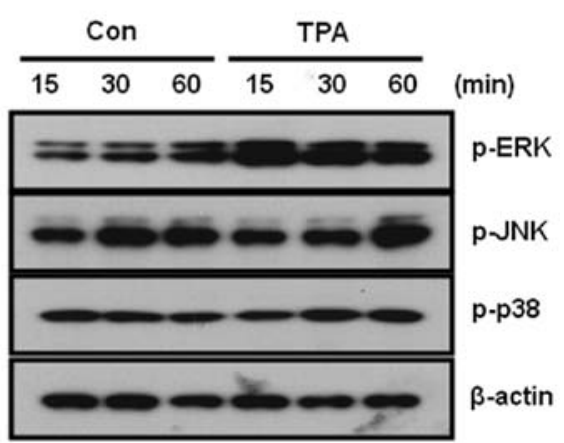

Figure 2. The phosphorylation of ERK1/2, JNK, and p38 in response to TPA in breast cancer cells. After serum starvation for $24 \mathrm{~h}, \mathrm{MCF}-7$ (A) and MDA-MB231 (B) breast cancer cells were treated with $20 \mathrm{ng} / \mathrm{ml}$ of TPA for the indicated times. The levels of ERK1/2, JNK, and p38 phosphorylation were analyzed by Western blotting. The results are representative of three independent experiments. Con, control.

Phosphorylation of ERK1/2, JNK, and 338 in response to TPA in breast cancer cells. To verify the regulatory mechanism of p53 and p21, we treated cells with $20 \mathrm{ng} / \mathrm{ml}$ of TPA for the indicated times. We showed that the phosphorylation of ERK1/2 and JNK was maximally increased by TPA at $15 \mathrm{~min}$. The phosphorylation of $\mathrm{p} 38$ was not affected by TPA in MCF-7 breast cancer cells (Fig. 2A). However, in MDA-MB-231 breast cancer cells, the phosphorylation of ERK1/2 was significantly increased by TPA, but not JNK and p38 (Fig. 2B). Therefore, we suggest that the MEK/ERK signaling pathway may play an important role on the expression of p53 and p21 in response to TPA in breast cancer cells.

Expression of p53 and $p 21$ mRNA by TPA is mediated by a $M E K / E R K$-dependent mechanism in breast cancer cells. To determine the signaling mechanism involved in the
TPA-induced up-regulation of p21 and the down-regulation of p53, MCF-7 with wild-type p53 and MDA-MB-231 with mutant p53 breast cancer cells were pre-treated with a MEK1/2 inhibitor (UO126), a JNK inhibitor (SP600125), or a p38 inhibitor (SB203580) for 30 min prior to TPA treatment, then treated with $20 \mathrm{ng} / \mathrm{ml}$ of TPA for $24 \mathrm{~h}$. As shown in Fig. 3A, the TPA-induced up-regulation of p21 and downregulation of p53 mRNA expression were reversed by UO126, but not by SP600125 and SB203580 in MCF breast cancer cells. In addition, TPA-induced p21 mRNA expression was decreased by UO126 in MDA-MB-231 breast cancer cells (Fig. 3B). However, the level of p53 mRNA expression was not changed by TPA and/or UO126 treatment (Fig. 3B). Therefore, we demonstrated that the TPA-induced up-regulation of p21 and down-regulation of p53 were mediated by a MEK/ ERK-dependent mechanism, although the expression of p53 
A

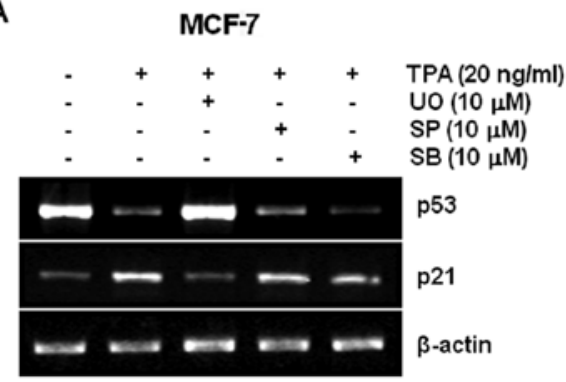

B

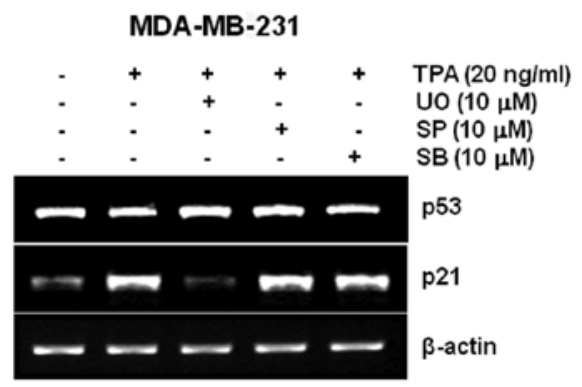

Figure 3. The expression of $\mathrm{p} 53$ and $\mathrm{p} 21 \mathrm{mRNA}$ by TPA is mediated by a MEK/ERK-dependent mechanism in breast cancer cells. After serum starvation for $24 \mathrm{~h}$, MCF-7 (A) and MDA-MB-231 (B) breast cancer cells were pre-treated with $10 \mu \mathrm{M}$ UO, SP, or SB for $30 \mathrm{~min}$, then they were treated with $20 \mathrm{ng} / \mathrm{ml}$ of TPA for $24 \mathrm{~h}$. The levels of p53 and p21 mRNA were analyzed by RT-PCR. The results are representative of three independent experiments. Con, control; UO, UO126; SP, SP600125; SB, SB203580.

A
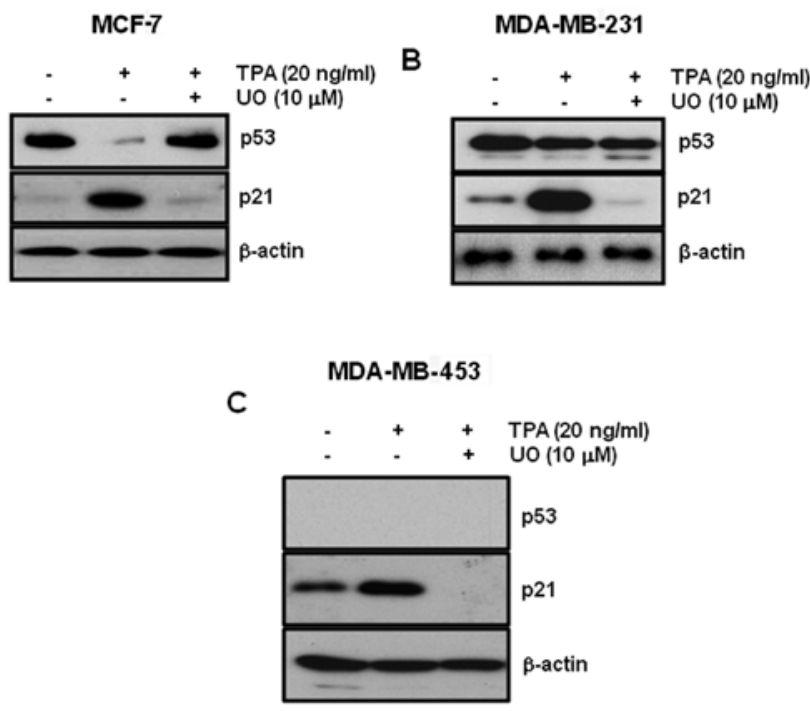

Figure 4. The TPA-induced up-regulation of p21 and down-regulation of p53 are reversed by UO126 in breast cancer cells. After serum starvation for $24 \mathrm{~h}$, MCF-7 (A), MDA-MB-231 (B), and MDA-MB-453 (C) breast cancer cells were pre-treated with $10 \mu \mathrm{M}$ UO for $30 \mathrm{~min}$, then treated with $20 \mathrm{ng} / \mathrm{ml}$ of TPA for $24 \mathrm{~h}$. The levels of expression of p53 and p21 protein were analyzed by Western blotting. The results are representative of three independent experiments. Con, control; UO, UO126.

mRNA was not affected by TPA in MDA-MB-231 breast cancer cells.

The TPA-induced up-regulation of $p 21$ and down-regulation of p53 are reversed by UO126 in breast cancer cells. To confirm the level of p53 and p21 protein expression in response to TPA, MCF-7 with wild-type p53, MDA-MB-231 with mutant p53, and MDA-MB-453 with p53 null breast cancer cells were pre-treated with UO126 for $30 \mathrm{~min}$ prior to TPA treatment, then treated with $20 \mathrm{ng} / \mathrm{ml}$ of TPA for $24 \mathrm{~h}$. Like the level of mRNA, the TPA-induced up-regulation of p21 was suppressed by UO126 in all of the cells (Fig. 4). In contrast, the TPA-induced down-regulation of $\mathrm{p} 53$ protein was increased by UO126 in MCF-7 breast cancer cells (Fig. 4A). However, the level of p53 protein expression was not changed by TPA and/or UO126 in MDA-MB-231 (mutant p53) and MDA-MB-453 (null p53) cells (Fig. 4B and C). In a previous study, Sheikh et al (19) reported that the $\mathrm{p} 21^{\mathrm{WAF} / \mathrm{CIPl}}$ protein is a critical downstream effector of p53 and overexpression of the $\mathrm{p} 21^{\mathrm{WAF} / \mathrm{CIP} 1}$ suppressed the cell division of MCF-7 breast cancer cells. Therefore, we also suggest that the TPA-induced expression of p21 may trigger the arrest of the cell cycle in breast cancer cells.

The TPA-induced G2/M arrest of the cell cycle is recovered by UO126 in breast cancer cells. To determine the involvement of the MEK/ERK signaling pathway on TPA-induced growth arrest of breast cancer cells, we pre-treated cells with $10 \mu \mathrm{M}$ UO126 prior to treatment of MCF-7 and MDA-MB231 cells with $20 \mathrm{ng} / \mathrm{ml}$ of TPA. After $24 \mathrm{~h}$, the cells were harvested and subjected to FACS analysis. Our results showed that TPA-treated cells significantly increased G2/M phase arrest compared with vehicle-treated control cells in MCF-7 and MDA-MB-231 cells (Fig. 5). The G2/M phase portion (30.5\%) was significantly increased by $12.5 \%$ of the control level with TPA treatment in MCF-7 breast cancer cells (Fig. 5A). However, the TPA-induced G2/M phase arrest of the cell cycle was decreased by $10.2 \%$ of the control level with UO126 treatment (Fig. 5A). We also confirmed these effects in MDA-MB-231 breast cancer cells. Like the MCF-7 cells, the TPA-induced G2/M phase portion (39.4\%) was significantly decreased by $7.8 \%$ of the control level with UO126 treatment (Fig. 5B). Therefore, we demonstrated that the TPA-induced G2/M phase growth arrest of the cell cycle was mediated through a MEK/ERK-dependent mechanism in breast cancer cells.

The levels of expression of $p 21$ and $p 53$ protein are regulated by $C A-M E K$ in breast cancer cells. Finally, we investigated the involvement of the MEK/ERK signaling pathway on the expression of p21 and p53 in breast cancer cells. Thus, we transiently transfected MCF-7 and MDA-MB-231 cells with Ad-Lac Z and Ad-CA-MEK for $24 \mathrm{~h}$, respectively, followed by further incubation for $24 \mathrm{~h}$ in serum-free media. Our results showed that the level of p53 protein expression was significantly decreased, whereas the level of p21 expression was increased by Ad-CA-MEK overexpression in MCF-7 breast cancer cells (Fig. 6A). In MDA-MB-231 cells, the level of expression of 533 protein was not changed by Ad-CA-MEK overexpression (Fig. 6B). However, under the same conditions, the expression of p21 protein was significantly increased 
A

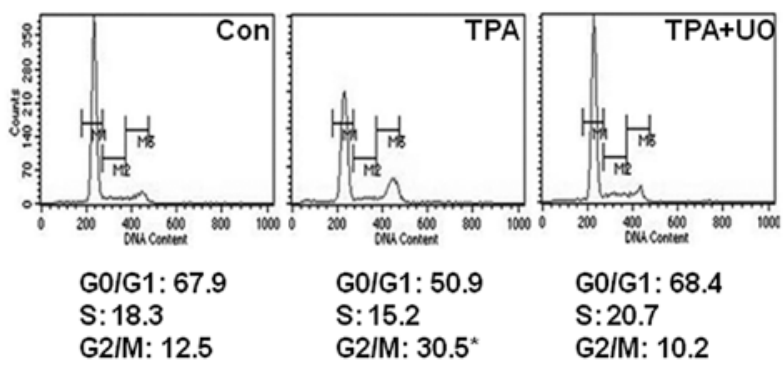

B

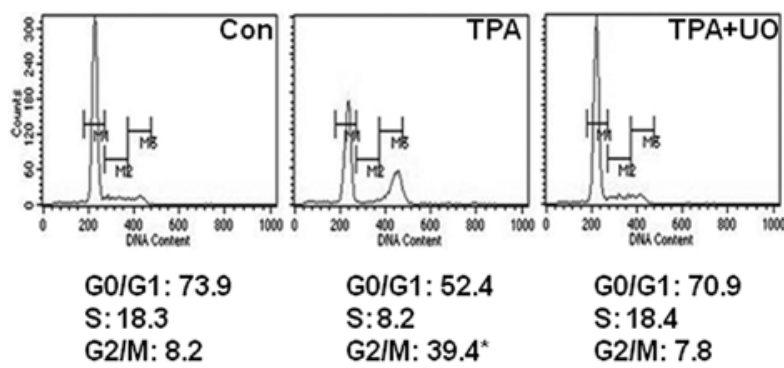

Figure 5. The TPA-induced G2/M arrest of the cell cycle is recovered by UO126 in breast cancer cells. After serum starvation for 24 h, MCF-7 (A) and MDA-MB-231 (B) breast cancer cells were pre-treated with $10 \mu \mathrm{M}$ UO for $30 \mathrm{~min}$, then treated with $20 \mathrm{ng} / \mathrm{ml}$ of TPA for $24 \mathrm{~h}$. The cell cycle was analyzed by FACS analysis, as described in Materials and methods. The results are representative of three independent experiments. Con, control; UO, UO126.
A

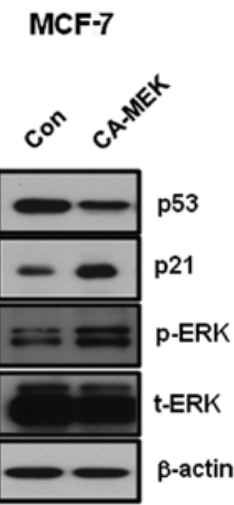

B MDA-MB-231

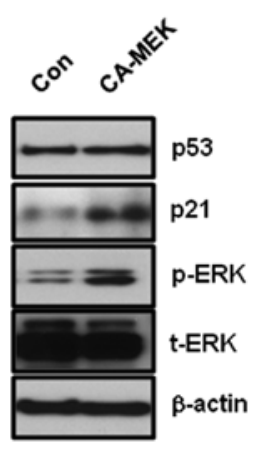

Figure 6. The levels of p21 and p53 protein expression are regulated by CA-MEK in breast cancer cells. After adenoviral (Ad)-Lac Z and Ad-CA-MEK infection for $24 \mathrm{~h}$ and serum starvation for $24 \mathrm{~h}, \mathrm{MCF}-7$ (A) and MDA-MB-231 (B) breast cancer cells were further incubated at $37^{\circ} \mathrm{C}$ for $24 \mathrm{~h}$ in serum-free media. Using whole cell lysates, the expression of p53, p21, p-ERK1/2, and $\beta$-actin was measured by Western blotting. These results are representative of three independent experiments. Con, control (Ad-Lac Z); CA-MEK, constitutively active-MEK.

(Fig. 6B). Therefore, we demonstrated that the MEK/ERK signaling pathway directly regulates the level of expression in p21 and p53 in breast cancer cells.

\section{Discussion}

Phorbol esters, such as TPA, are natural molecules that are well-known tumor promoters and reversible activators of PKC (20). TPA has a differential effect on a variety of cells (21). TPA significantly increases cell proliferation in fibroblasts, epidermal cells, and several cancer cell lines, such as KG-1 human myeloblastic leukemia cells and ZR75-1 human breast cancer cells $(22,23)$. However, TPA-induced activation of PKC suppresses the cell growth of non-small cell lung cancer cells and DanG pancreatic cancer cells $(21,24)$. Although the role of TPA on the regulation of the cell cycle is controversial, we also found that TPA triggers the arrest of $\mathrm{S}$ to G2/M transition in MCF-7 and MDA-MB-231 breast cancer cells.

The induction of $\mathrm{p} 21^{\text {waf1/cipl }}$ expression during differentiation has been observed in monocytes and macrophages, such as U937, ML-1, and HL60 cells by TPA treatment $(25,26)$. $\mathrm{p} 21^{\text {waf } 1 / \text { cip } 1}$ is known to bind cyclin-cdk complexes to inhibit kinase activities and suppresses $\mathrm{Rb}$ protein phosphorylation to inhibit cell division $(27,28)$. Overexpression of $\mathrm{p} 21^{\text {waf } 1 / \mathrm{cip} 1}$ has been reported to suppress the proliferation of cancer cells through the inactivation of cyclin D1-cdk in melanoma and prostate cancer cells $(29,30)$. Consistent with these reports, our results showed that TPA significantly increases the level of p21 mRNA and protein expression in MCF-7, MDA-MB-231, and MDA-MB-453 breast cancer cells. Therefore, we demonstrated that enhanced p21 by TPA may augment the G2/M phase arrest of the cell cycle in MCF-7 and MDA-MB-231 breast cancer cells.

Induction of p21 by DNA damage is mediated through the binding of p53 in the p21 promoter (6). However, the level of p21 expression is greatly enhanced by PMA treatment in HL-60 leukemia cells lacking p53 (27). Our results showed that TPA-induced the up-regulation of p21 in both MDA-MB231 with mutant p53 and MDA-MB-453 with p53 null, which is evidence that TPA-induced $\mathrm{p} 21$ expression may be regulated through a p53-independent mechanism.

The PMA-induced phosphorylation of ERK significantly increases AP-1 DNA binding activity, then promotes cell proliferation through the induction of cyclin D1 in CCL39 cells (31). However, the diterpene ester-induced activation of ERK is mediated by PKC activation and leads to cellular senescence through an ERK-dependent p21 induction in melanoma cells (32). Our results showed that the TPA-induced G2/M phase arrest and induction of $\mathrm{p} 21$ is reversed by a MEK inhibitor (UO126) in MCF-7 and MDA-MB-231 breast cancer cells. Therefore, we suggest that the cell cycle arrest and p21 induction by TPA is regulated through a MEK/ERK-dependent pathway in breast cancer cells.

In previous studies, Chen et al (33) reported that selenocystine $(\mathrm{SeC})$-induced $\mathrm{S}$-phase arrest is associated with suppression of cyclin D1, and CDK4 and 6, with concomitant induction of p21, p27, and p53 through a PI3K/Akt- and MAPK-dependent pathway in MCF-7 breast cancer cells. The leptin-induced down-regulation of p53 is mediated through the JAK2/PI-3K and Akt-MEK/ERK pathways in ZR-75-1 breast cancer cells (33). In agreement with these reports, our results also showed that the TPA-induced down-regulation of p53 is suppressed by UO126 treatment, but not by SP600125 or SB203580. In contrast, the basal level of p53 expression was 
significantly increased by CA-MEK overexpression in MCF-7 breast cancer cells. Therefore, we demonstrated that the MEK/ ERK pathway directly regulates the transcriptional activity of p53 in MCF-7 breast cancer cells.

In the current study we determined the role of TPA in the regulation of the cell cycle and the regulatory mechanism of a differential expression of $\mathrm{p} 53$ and $\mathrm{p} 21$ by TPA in breast cancer cells. We found that the levels of expression of p53 and p21 are reciprocally regulated by TPA treatment in MCF-7 breast cancer cells with wild-type p53. In addition, the TPA-induced $\mathrm{G} 2 / \mathrm{M}$ arrest, up-regulation of $\mathrm{p} 21$, and down-regulation of $\mathrm{p} 53$ was reversed by a MEK1/2 inhibitor (UO126), but not by a JNK inhibitor (SP600125), or a p38 inhibitor (SB203580). Taken together, we demonstrated that the opposite regulation of p53 and p21 by TPA is mediated through a MEK/ERK-dependent pathway in MCF-7 cells. Thus, TPA-induced p21 expression triggers $\mathrm{G} 2 / \mathrm{M}$ phase arrest of the cell cycle in breast cancer cells.

\section{Acknowledgements}

This study was supported by a grant from the Korea Healthcare Technology R\&D Project, Ministry for Health \& Welfare Affairs, Republic of Korea (A092255).

\section{References}

1. Wen-Sheng W: Protein kinase $\mathrm{C}$ alpha trigger Ras and Raf-independent MEK/ERK activation for TPA-induced growth inhibition of human hepatoma cell HepG2. Cancer Lett 239: 27-35, 2006.

2. Shimao Y, Nabeshima K, Inoue T and Koono M: TPA-enhanced motility and invasion in a highly metastatic variant (L-10) of human rectal adenocarcinoma cell line RCM-1: selective role of PKC-alpha and its inhibition by a combination of PDBu-induced PKC downregulation and antisense oligonucleotides treatment. Clin Exp Metastasis 17: 351-360, 1999.

3. Schlingemann J, Hess J, Wrobel G, et al: Profile of gene expression induced by the tumour promotor TPA in murine epithelial cells. Int J Cancer 104: 699-708, 2003.

4. Kim S, Lee HS, Lee SK, et al: 12-O-Tetradecanoyl phorbol13-acetate (TPA)-induced growth arrest is increased by silibinin by the down-regulation of cyclin $\mathrm{B} 1$ and cdc2 and the up-regulation of p21 expression in MDA-MB-231 human breast cancer cells. Phytomedicine 17: 1127-1132, 2010.

5. Salabat MR, Ding XZ, Flesche JB, et al: On the mechanisms of 12-O-tetradecanoylphorbol-13-acetate-induced growth arrest in pancreatic cancer cells. Pancreas 33: 148-155, 2006.

6. el-Deiry WS, Tokino T, Velculescu VE, et al: WAF1, a potential mediator of p53 tumor suppression. Cell 75: 817-825, 1993.

7. Weiss RH: p21Waf1/Cip1 as a therapeutic target in breast and other cancers. Cancer Cell 4: 425-429, 2003.

8. Li Y, Dowbenko D and Lasky LA: AKT/PKB phosphorylation of p21Cip/WAF1 enhances protein stability of p21Cip/WAF1 and promotes cell survival. J Biol Chem 277: 11352-11361, 2002.

9. Lawlor MA and Rotwein P: Insulin-like growth factor-mediated muscle cell survival: central roles for Akt and cyclin-dependent kinase inhibitor p21. Mol Cell Biol 20: 8983-8995, 2000.

10. Asada M, Yamada T, Ichijo H, et al: Apoptosis inhibitory activity of cytoplasmic p21(Cip1/WAF1) in monocytic differentiation. EMBO J 18: 1223-1234, 1999.

11. Fan Y, Borowsky AD and Weiss RH: An antisense oligodeoxynucleotide to $\mathrm{p} 21$ (Waf1/Cip1) causes apoptosis in human breast cancer cells. Mol Cancer Ther 2: 773-782, 2003.

12. Sherr CJ and Roberts JM: CDK inhibitors: positive and negative regulators of G1-phase progression. Genes Dev 13: 1501-1512, 1999.
13. Sugrue MM, Shin DY, Lee SW and Aaronson SA: Wild-type p53 triggers a rapid senescence program in human tumor cells lacking functional p53. Proc Natl Acad Sci USA 94: 9648-9653, 1997.

14. Sur S, Pagliarini R, Bunz F, et al: A panel of isogenic human cancer cells suggests a therapeutic approach for cancers with inactivated p53. Proc Natl Acad Sci USA 106: 3964-3969, 2009.

15. Woods DB and Vousden KH: Regulation of p53 function. Exp Cell Res 264: 56-66, 2001.

16. Petitjean A, Mathe E, Kato S, et al: Impact of mutant p53 functional properties on TP53 mutation patterns and tumor phenotype: lessons from recent developments in the IARC TP53 database. Hum Mutat 28: 622-629, 2007.

17. Dittmer D, Pati S, Zambetti G, et al: Gain of function mutations in p53. Nat Genet 4: 42-46, 1993.

18. Hsiao M, Low J, Dorn E, et al: Gain-of-function mutations of the p53 gene induce lymphohematopoietic metastatic potential and tissue invasiveness. Am J Pathol 145: 702-714, 1994.

19. Sheikh MS, Rochefort $\mathrm{H}$ and Garcia M: Overexpression of p21WAF1/CIP1 induces growth arrest, giant cell formation and apoptosis in human breast carcinoma cell lines. Oncogene 11: 1899-1905, 1995.

20. Kikkawa U, Takai Y, Tanaka Y, Miyake R and Nishizuka Y: Protein kinase $\mathrm{C}$ as a possible receptor protein of tumorpromoting phorbol esters. J Biol Chem 258: 11442-11445, 1983.

21. Detjen KM, Brembeck FH, Welzel M, et al: Activation of protein kinase $C$ alpha inhibits growth of pancreatic cancer cells via p21(cip)-mediated G(1) arrest. J Cell Sci 113 (Pt 17): 3025-3035, 2000.

22. Agadir A, Chen G, Bost F, Li Y, Mercola D and Zhang X: Differential effect of retinoic acid on growth regulation by phorbol ester in human cancer cell lines. J Biol Chem 274: 29779-29785, 1999.

23. Koeffler HP: Human myelogenous leukemia: enhanced clonal proliferation in the presence of phorbol diesters. Blood 57: 256-260, 1981.

24. Tahara E, Kadara H, Lacroix L, Lotan D and Lotan R: Activation of protein kinase $\mathrm{C}$ by phorbol 12-myristate 13 -acetate suppresses the growth of lung cancer cells through KLF6 induction. Cancer Biol Ther 8: 801-807, 2009.

25. Schwaller J, Peters UR, Pabst T, et al: Up-regulation of p21WAF1 expression in myeloid cells is activated by the protein kinase $\mathrm{C}$ pathway. Br J Cancer 76: 1554-1557, 1997.

26. Ullmannova V, Stockbauer P, Hradcova M, Soucek $J$ and Haskovec C: Relationship between cyclin D1 and p21(Waf1/ Cip1) during differentiation of human myeloid leukemia cell lines. Leuk Res 27: 1115-1123, 2003.

27. Das D, Pintucci G and Stern A: MAPK-dependent expression of p21(WAF) and p27(kip1) in PMA-induced differentiation of HL60 cells. FEBS Lett 472: 50-52, 2000.

28. Blagosklonny MV, Prabhu NS and El-Deiry WS: Defects in p21WAF1/CIP1, Rb, and c-myc signaling in phorbol esterresistant cancer cells. Cancer Res 57: 320-325, 1997.

29. Coppock DL, Buffolino P, Kopman C and Nathanson L: Inhibition of the melanoma cell cycle and regulation at the G1/S transition by 12-O-tetradecanoylphorbol-13-acetate (TPA) by modulation of CDK2 activity. Exp Cell Res 221: 92-102, 1995.

30. Sugibayashi R, Shimizu T, Suzuki T, Yamamoto N, Hamada $H$ and Takeda K: Upregulation of p21(WAF1/CIP1) leads to morphologic changes and esterase activity in TPA-mediated differentiation of human prostate cancer cell line TSU-Pr1. Oncogene 20: 1220-1228, 2001.

31. Balmanno K and Cook SJ: Sustained MAP kinase activation is required for the expression of cyclin D1, p21Cip1 and a subset of AP-1 proteins in CCL39 cells. Oncogene 18: 3085-3097, 1999.

32. Cozzi SJ, Parsons PG, Ogbourne SM, Pedley J and Boyle GM: Induction of senescence in diterpene ester-treated melanoma cells via protein kinase C-dependent hyperactivation of the mitogenactivated protein kinase pathway. Cancer Res 66: 10083-10091, 2006.

33. Chen C, Chang YC, Liu CL, Chang KJ and Guo IC: Leptininduced growth of human ZR-75-1 breast cancer cells is associated with up-regulation of cyclin D1 and c-Myc and downregulation of tumor suppressor p53 and p21WAF1/CIP1. Breast Cancer Res Treat 98: 121-132, 2006. 